\title{
Rule-Based Systems for Decision Support and Decision-Making in Dutch Legal Practice. A Brief Overview of Applications and Implications
}

\section{Author(s)}

Timmer, Ivar; Rietveld, Rachel

\section{DOI}

10.3917/drs1.103.0517

\section{Publication date}

2019

\section{Document Version}

Author accepted manuscript (AAM)

\section{Published in}

Droit et societe

\section{Link to publication}

\section{Citation for published version (APA):}

Timmer, I., \& Rietveld, R. (2019). Rule-Based Systems for Decision Support and Decision-Making in Dutch Legal Practice. A Brief Overview of Applications and Implications. Droit et societe, 2019(3), 517-534. [103]. https://doi.org/10.3917/drs1.103.0517 


\section{Inhoud}

1. Introduction

2. Methodology

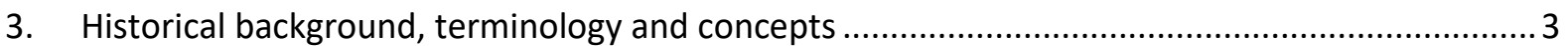

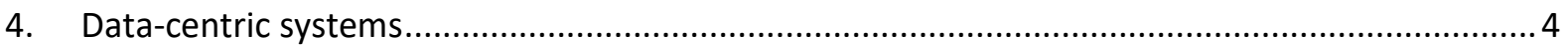

5. Rule-based systems in Dutch legal practice ........................................................................... 6

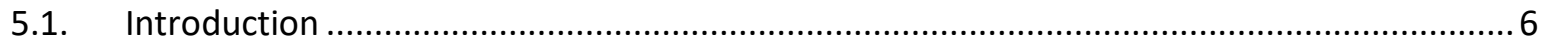

5.2. Rule-based systems for mass administrative decision-making .........................................6

5.3. Systems for use by government or corporate legal departments ..................................... 8

5.4. Systems for legal advice and legal aid to private individuals............................................10

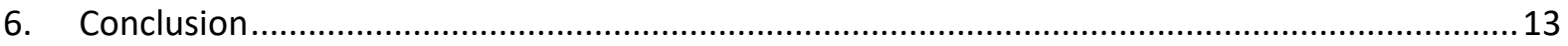

\section{Rule-based systems for decision support and decision-making in Dutch legal practice}

\section{A brief overview of applications and implications}

Ivar Timmer, Rachel Rietveld ${ }^{1}$

\section{Introduction}

In the light of law's ancient history, digitization and information technology are recent phenomena. Although over the past three decades legal practice has certainly changed under the influence of technology, the approach towards the adoption of technology has long remained predominantly conservative. In recent years, however, several factors appear to push organizations and legal practice to explore the possibilities that information technology offers. In fact, legal tech has become a buzzword. A quick internet search reveals a world of conferences, blogs, workshops and videos on the subject. Although legal tech certainly has the characteristics of a hype, there is a growing number of examples where technology is successfully being applied in legal practice. Because of several factors that we will address in this article, we consider it a good sign that academic interest, although still relatively low, increases as well. The establishment of several legal tech labs at universities worldwide could be regarded as indications of this increased academic interest. ${ }^{2}$

\footnotetext{
${ }^{1}$ Rachel Rietveld is one the lead developers of an expert system for dismissal law, available at www.magontslag.nl, developed by a branch of the University of Amsterdam. Ivar Timmer is an associate professor in the field of legal management and legal service design at the Amsterdam University of Applied Sciences and initiator of the Legal Tech Alliantie HBO-Rechten: an alliance between 11 (LLB-programs at) Dutch universities of applied sciences in the field of legal tech. Both lecture on legal tech at their respective institutions, train legal professionals in the use of legal technology and speak regularly on the subject for professional audiences.

2 See, for instance, the Legal Tech Lab at the University of Helsinki, https://www.helsinki.fi/en/networks/legal-tech-lab, the Legal Tech Laboratory at the UMKC Law School (Kansas City), http://www.thelegaltechlab.com/, the Law Lab at Illinois Tech, Chicago-Kent College of Law, http://www.thelawlab.com/ and the Legal Tech Lab at the Amsterdam University of Applied Sciences of Amsterdam (opening in 2019). This special issue of Droit et Société is of course evidence in itself of the growing interest in the subject.
} 
Legal tech is an ill-defined concept ${ }^{3}$, which has considerable overlap with related phenomena such as GovTech, InSurtech and FinTech ${ }^{4}$. For the purposes of this article, we consider legal tech all forms of specialized software that, in short, have been developed especially for legal practice. ${ }^{5}$ By this definition, specialized databases that make information on jurisprudence and legislation available to legal professionals are a form of legal tech, while Google is not. Database software designed specifically for contract management is a form of legal tech, while Microsoft Office applications are not. In this article, we explore the current state of affairs in Dutch legal practice with regard to a specific form of legal tech: Rule-based systems for legal decision support or decision-making. For the sake of brevity, we will sometimes simply call them rule-based systems or decision support systems.

The technology behind rule-based systems is -in essence- relatively straightforward and has been around for decades. Much of current academic interest in legal informatics is geared towards technologically more advanced data-centric systems, which we will discuss briefly in paragraph 4. Nevertheless, as we will discuss in the following paragraph, rule-based systems are frequently - and increasingly - being used in legal practice and for the foreseeable future could thus be regarded as one of the most important forms of legal tech.

Government agencies have been using rule-based systems to support (mass) legal decision-making for decades. With the continuing digitization of government and increased possibilities for the exchange of data, their use can only be expected to increase. As we will discuss in this article, Dutch legal practice has also seen a clear increase of the use of rule-based systems by legal departments, law firms, legal publishers and by various other parties that use rule-based systems to improve the provision of legal aid to private individuals. Although still quite small-scale, these developments will, with the steady increase of the use of these systems, eventually have an important impact on legal practice and therefore justify scientific attention. In this article, we will give an overview of some important areas of Dutch legal practice where rule-based systems for decision support or decision-making are currently being used. We will discuss benefits, challenges and pitfalls of the use of these systems in practice and look towards future developments.

The structure of this article is as follows. In paragraph 2 we discuss the methodology. In paragraph 3 , we briefly sketch the historical background of rule-based systems and explain some important terminology and concepts. In paragraph 4, we discuss the main characteristics of data-centric systems that in a different fashion could also be deployed for legal decision support. In paragraph 5 we will discuss the use of rule-based systems in various areas of legal practice. In paragraph 6 we will draw some general conclusions and identify topics for future research. Although our focus is on Dutch legal practice, many of the developments we describe will reflect the situation in other, and specifically Western, countries.

\section{Methodology}

This article is based on literature review, a series of interviews, as well as our own professional experiences. In 2018, we interviewed a total of 15 professionals and academics from Dutch legal practice. Most were actively involved in the design, implementation or use of decision support systems for internal use within their own organization, or were working for legal publishers or other legal service providers that offered systems to clients (businesses or consumers). Three were academics, studying aspects of rule-based systems in legal practice.

\footnotetext{
${ }^{3}$ See Markus Hartung, Micha-Manuel Bues and Gernot Halbleib, Legal Tech, How Technology is Changing the Legal World, A Practitioner's Guide, München: Beck, 2018, p. 5, for a discussion of proposed definitions.

${ }^{4}$ Technology for the governmental, insurance and financial sectors, respectively.

${ }^{5}$ There are always grey areas. Some software that is generally regarded as legal tech may also have other relevant target groups. Do-it-yourself software for decision support systems, for example, is also used by professionals in other knowledge-intensive sectors, such as tax, medicine and accountancy. It is not, however, mainstream software and is used in a specialized manner by legal professionals.
} 
The majority of professionals working in legal practice focused on contract automation, but several were involved in rule-based decision support systems outside the area of contracts, such as systems that informed consumers or businesses about their legal rights and obligations. We did semistructured interviews, asking these professionals about their views on past, current and future developments with regard to these systems and related subjects. We asked them to identify (possible) good practices and pitfalls with regard to the design and implementation of these systems and questioned them about their views on the possible implications of these systems for the labor market for legal professionals, both quantitatively and qualitatively. Not all subjects were equally prominent in all interviews and many of the interviews also covered some related topics, such as the commercial impact of expert systems on the market for legal services or the general progress in artificial intelligence and text mining.

\section{Historical background, terminology and concepts}

The work on rule-based systems in legal practice started in the 1970s. James Sprowl is considered to have written the first article on the subject. ${ }^{6}$ The prospect of automating legal reasoning sparked a great deal of enthusiasm. In the 1980s, several universities in the Netherlands established research groups in legal informatics, creating an active (inter)national network of researchers ${ }^{7}$ in the field of artificial intelligence and law. Reflecting the international situation, expectations of this new field were high and the climate for acquiring research funds was favorable. In this period, rule-based legal expert systems were the center of attention. A legal expert system emulates the analytical and decisionmaking ability of a human expert in the field of law. Users of the system will fill in a questionnaire, after which the system will provide them with an answer to a certain legal question, or provide them with customized legal documentation. Systems like this were, among other things, expected to be able to improve quality, cost-effectiveness and/or accessibility of legal advice or decision-making. ${ }^{8}$ The systems are called rule-based, because they use a deductive approach (or: rules-based logic) to reach conclusions from a set of rules, with a 'modus ponens' or 'if... then...-character'. ${ }^{9}$ They employ a knowledge base that is compiled using expertise and knowledge from legal experts, and an inference engine: the component that contains the logical rules and applies them to the knowledge base. ${ }^{10}$ Because of the central role of knowledge acquisition, storage and retrieval another common term for these types of systems is 'knowledge-based-systems'. ${ }^{11}$

In the late 80 s and $90 \mathrm{~s}$ In the Netherlands, as elsewhere, , several initiatives were taken. Rotterdam's Erasmus University, for example, started the JURICAS project: A user-interactive system in several areas of law that would ask the user all criteria considered relevant for a specific case, and came up with an advice as result. ${ }^{12}$ According to their publication, over a hundred lawyers used the system in

\footnotetext{
6 James Sprowl, Automating the Legal Reasoning Process: A Computer That Uses Regulations and Statutes to Draft Legal Documents, Law and Social Inquiry, Journal of the American Bar Foundation, 4 (1), 1979, p. 1-81.

7 The JURIX-foundation for legal knowledge-based systems was founded in this period, www.jurix.nl

${ }^{8}$ See also, Ivar Timmer, Contract automation: Experiences from Dutch Legal Practice, paragraph 3.2 in: Marcelo Corrales, Mark Fenwick, Helena Haapio, Legal Tech, Smart Contracts and Blockchain, A global perspective on recent industry, regulatory and legal developments in the "Blockchain space", Berlin: Springer, 2019 (expected)

${ }^{9}$ See for a deeper insight of logic applied to law e.g. Qiaoting Zhong e.a., 'An explainable multi-attribute decision model based on argumentation' in Expert Systems With Applications, Vol. 117, 2018. Available at Sciencedirect

(www.elsevier.com/locate/aswa). Since there is no scientifically background in legal reasoning, many authors tried to explain how it works or should work, in an attempt to substantiate the success of doing so.

${ }^{10} \mathrm{Karl}$ Branting, 'Data-centric and logic-based models for automated legal problem solving', in: Artificial Intelligence and Law, 2017 vol. 25(1), p. 7

${ }^{11}$ N.B.Bilgi \& Dr.R.V.Kulkarni, 'An Investigative Survey of Application of Knowledge

Based System in Legal Domain', 2008, International Journal of Information Technology and Knowledge

Management, ISSN NO 0973-4414, pp-517-525

12 R.V. de Mulder e.a., 'Knowledge Systems and the Law: The JURICAS Project', Expert System With Applications, Vol. 4, 1992.
} 
their practice. Both in the Netherlands and in other countries, however, after initial excitement, most initiatives were followed by disappointment, due to several factors. In general, maintaining systems proved complex and resource-intensive. Developers often had high ambitions, but the systems proved unable to completely mimic the analyses or decisions of human legal experts and worked best in situations with relatively clear rules and inputs. Leith writes that around the year 2000, most researchers had replaced the term expert system by systems for decision support, because the former was considered too ambitious. He states that another important reason for the disappointing results was 'a focus on the machine, rather than on the user'. ${ }^{13}$ The fact that high expectations were not met triggered an 'Al-winter': a steep decline in academic attention and funding for legal informatics and expert systems. Research groups at many Dutch universities disappeared and a lot of expertise dissolved, which universities might regret in the current, renewed attention for legal tech.

The experiences from these years are valuable. Some of the failures that respondents in our research have experienced still seem due to similar main causes, especially: Insufficient analysis of user needs and underlying processes. Nevertheless, there are also significant differences. Society and legal practice were far less digitized than they are today and legal information was still primarily available on paper only. Obviously, this situation has changed completely in the Netherlands, as elsewhere. Processes within organizations have also been digitized to a large extent and will continue to digitize. Legal departments and legal service providers have to attune their services to this new reality. Our research indicates that this creates more favorable conditions for decision support systems to be successful, although there are still many challenges to overcome.

\section{Data-centric systems}

We briefly explain these types of systems, because they could also provide a form of decision support. In our experience, legal professionals sometimes find it difficult to distinguish between these two types of applications. The central difference is that rule-based systems depart from the expertise of legal professionals, which is consequently 'programmed in the computer' using logical rules: 'Computerized legal advisory systems' ${ }^{14}$. Data-centric systems take a different approach and use methods and techniques from natural language processing, text mining and data science to analyze large amounts of legally relevant data, such as contracts, legislation, jurisprudence or other (legal) texts ${ }^{15}$. Data-centric systems are usually partly trained by human legal experts, who tell the system whether generated outcomes are correct: Supervised machine learning.

E-discovery software could be considered a branch of data-centric systems. Traditionally developed for the discovery process in US civil litigation, this type of application is currently used in many situations that require legal research (fraud, anti-competition, due diligence, etcetera), because of its capability to filter, sort, categorize and analyze relevant information. In due diligence investigations and similar types of research-, these types of applications can significantly reduce the amount of work that has to be done by legal professionals. According to Remus and Levy, $85 \%$ of all lawyers' hours spent on document review could be done by automated systems. ${ }^{16}$ US legal practice has established that the combination of man and machine is more effective and efficient in performing this type of

\footnotetext{
${ }^{13}$ See Philip Leith, 'The Rise and the Fall of the Legal Expert System', European Journal of Law and Technology 1(1), 2010, url: http://ejlt.org/article/view/14/1: "What was missing was proper analysis of user needs - vital in any other area of computer implementation, but apparently viewed as unnecessary by the Al community. This produced a mismatch between what the experimenter believed the user wanted and what the user would actually use."

${ }^{14}$ Graham Greenleaf, 'Legal expert systems - robot lawyers?', presented at the Australian Legal Convention, Sydney, August 1989.

${ }^{15}$ See Bart Custers and Frans Leeuw, Legal big data. Toepassingen voor de rechtspraktijk en juridisch onderzoek, Nederlands Juristenblad 2017/1854, volume 34, p. 2449-2456 for an overview of applications of data-centric software in legal practice.

${ }^{16}$ Dana Remus and Frank Levy, Can Robots Be Lawyers? Computers, Lawyers, and the Practice of Law, 2016. Available at SSRN: https://ssrn.com/abstract=2701092 or http://dx.doi.org/10.2139/ssrn.2701092
} 
document review and the American Bar Association publishes regularly on best practices in this respect. ${ }^{17}$

ROSS, 'the robot lawyer' ${ }^{18}$, may be regarded as another example of a data-centric system. It uses natural language processing, combined with other techniques, to enable legal professionals to ask legal research questions using natural language. Various Dutch companies and publishers have some sort of pilot or prototype running that works in a similar manner as ROSS. ${ }^{19}$ In general, data-centric techniques and applications can be extremely useful in the new area of litigation assistance ${ }^{20}$, where software applications aim to provide users with information about the past behavior of particular attorneys, judges, forums, courts, etcetera to better estimate the chances of success by analyzing large volumes of historic cases. Ravel law ${ }^{21}$, Lex Machina ${ }^{22}$ and Premonition ${ }^{23}$ are examples of US providers, while SemLab ${ }^{24}$, LexIQ ${ }^{25}$ and Walter ${ }^{26}$ are Dutch examples. These types of applications expand the traditional areas of legal research by legal professionals while assessing cases. A practical obstacle in the Netherlands is that currently, after anonymization, only a small percentage of jurisprudence is published and in any way summarily described. This situation might change in the near future, opening up more possibilities for the use of data science techniques by legal practitioners and legal scholars.

Similar data-centric techniques were used in more academic settings to develop systems that predict judicial decisions. The research that involved systems for the prediction of decisions of the European Court of Human Rights ${ }^{27}$ and the US Supreme Court ${ }^{28}$ gained quite some attention, also from mainstream media. ${ }^{29}$ It is our impression that legal professionals with no or only basic technological knowledge sometimes believe that these results mean that it will be possible to replace judges in the near future. This is not the case. For example, in the ECHR-research, accuracy was only $79 \%$. This is a low rate, considering that the Court in $84 \%$ of the cases rules there is a violation of an article. ${ }^{30}$ Furthermore, the question to be predicted was boiled down to a 'yes-no question'. As Prakken explains: A person who consistently gives an affirmative answer to the question whether there is a breach of an article of the convention, scores better than the system. Moreover, predicting the result of a case $a$ is completely different from adjudicating a case. These important nuances do not mean that we believe that this type of research is not valuable. By contrast, applying data-science techniques to case law -or other areas of legal practice- may reveal relevant patterns and processes that are otherwise hard or impossible to discern for legal scholars. Hence, data-centric techniques are a very interesting development ${ }^{31}$, but are not about to take over legal practice.

Without going into the technical details, one of the most important disadvantages of using datacentric techniques in legal practice is that, at least to a certain extent, they are "black boxes". This

\footnotetext{
${ }^{17}$ See e.g. https://www.americanbar.org/groups/litigation/resources/e-discovery/

18 https://rossintelligence.com/

${ }^{19}$ E.g. legal publishers like Wolters Kluwer and Sdu, part of the French ELS, are. SemLab is experimenting with a new version of JuriBot to predict the outcome of a specific case.

20 Supra note 8, p. 13

${ }^{21}$ https://home.ravellaw.com/

22 https://lexmachina.com/

23 https://premonition.ai/

24 https://www.semlab.nl

25 https://www.lexiq.nl/lexiq-litigator

${ }^{26} \mathrm{https}: / / w w w . w a l t e r l e g a l . n l$

${ }^{27}$ Aletras e.a., 'Predicting judicial decisions of the European Court of Human Rights: a Natural Language Processing perspective, 2016, PeerJ Computer Science 2:e93.

28 D.M. Katz, M.J. Bommarito \& J. Blackman, 'A general approach for predicting the behavior of the Supreme Court of the United States', 2017 PLoS ONE 12(4): e0174698

${ }^{29}$ See for example https://www.bbc.com/news/technology-37727387

${ }^{30}$ Henry Prakken, 'Komt de robotrechter eraan', Nederlands Juristenblad 2018, afl. 4.

${ }^{31}$ See also, Corien Prins \& Jurgen van der Roest 'Al en de rechtspraak, Meer dan alleen de 'robotrechter', Nederlands Juristenblad 2018, afl. 4, p. 260-268
} 
means that when these advanced techniques are used, it is often fundamentally impossible to determine exactly how they arrive at certain results or predictions. As Branting ${ }^{32}$ writes: 'These techniques typically are opaque and unable to support the rule-governed discourse needed for persuasive argumentation and justification'. This is an essential difference with rule-based systems, which in essence are transparent and completely programmed by human experts. Of course, in practice, complex rule-based systems may come across as "black boxes" to lay users and may certainly contain errors or biases, but specialists will be able to track how the system produces its results, see also paragraph 5.2. This is a fundamental difference between rule-based and data-centric systems. Rule-based systems are man-made systems, in which experts have applied logic to law, trying to conceive all possible scenarios and programming the system accordingly. In data-centric systems, the machine performs part of the work in a black-box manner. It will and cannot reveal the actual process. Data-centric systems are useful and may be combined with rule-based systems to increase overall effectiveness, but their opaqueness is an important practical obstacle to their use for certain legal tasks.

\section{Rule-based systems in Dutch legal practice}

\subsection{Introduction}

In this brief overview of Dutch legal practice, we discuss some of the most important areas where rule-based decision support systems are currently being deployed. In the next subparagraph, we will first discuss systems for mass administrative decision-making. These latter systems mainly automate important, but relatively simple legal decisions, which, before being automated, were carried out by administrative professionals without a legal background. Although legal professionals are certainly involved in the design and maintenance of these systems and, for example, legal aid professionals will regularly challenge decisions made by these systems, the systems are relatively far from the direct environment of legal professionals and do not replace their work. However, rule-based systems for mass administrative decision-making do play an important part in legal practice and have recently been getting more scientific attention in the Netherlands.

In paragraph 5.3 we will then turn to the way rule-based systems for decision support are used by governmental or corporate legal departments. An interesting development in the last 10-15 years, is the arrival of 'do it yourself' software (DIY software) on the market for creating systems for decision support. Some examples of providers of this type of software are Neota Logic, HotDocs and Contract Express. Examples of Dutch providers are Berkeley Bridge, WeAgree, LegalThings and Juriblox. Before the arrival of this type of software, rather advanced computer skills were necessary to build these types of systems. DIY software has made this much easier and within the reach of non-tech savvy legal professionals. Legal departments are, for example, using this software for the triage of legal questions of other professionals within the organization, to support the creation of routine legal documents and to responsibly delegate other forms of relatively simple legal work to other departments. Although the complexity of these systems is usually relatively low, they can be very effective in improving in-house legal services.

Finally, in subparagraph 5.4 we will discuss systems for legal advice or legal aid, in the fields of consumer law, family law and labor law. Some of these systems are extremely complex. They come closest to what most would consider 'true' expert systems, combining large amounts of legal knowledge and expertise with the ability to partly replace the work of legal professionals.

\subsection{Rule-based systems for mass administrative decision-making}

Rule-based systems are only able to fully automate decisions in situations where data are objective and available and choices are binary: Above or under a certain age, income, speed, etcetera.

\footnotetext{
${ }^{32}$ Supra note 10
} 
Automated traffic penalties are an example of fully automated legal decisions. Because many administrative decisions are of a binary nature, the Dutch government uses rule-based systems extensively to support or automate the execution of legislation. Full or near-full automation is most prevalent in administrative decisions on the financial rights and obligations of citizens and organizations in the areas of social security, social benefits and tax. Several Dutch governmental agencies, such as the Employee Insurance Agency ${ }^{33}$, the Tax and Customs Administration ${ }^{34}$ and the Social Insurance Bank ${ }^{35}$ play a crucial role in the Dutch economic system, by reallocating over 150 billion euros annually, mainly through these types of processes ${ }^{36}$. Many of the administrative processes of these organizations are interlinked, in the sense that decisions by one agency are based on data provided by another agency ("chain decisions").

There can be no doubt that automating administrative decisions has many advantages. From a perspective of legal quality, unlike humans, a rule-based system will always act consistently. Automation is cost-efficient and can increase speed and user-friendliness. In fact, a modern government could not function properly without automation. Nevertheless, automation also has its disadvantages. Van Eck, after studying automated administrative chain decisions regarding a financial interest in Dutch legal practice, concluded that the use of rule-based systems diminishes the role of street-level bureaucrats in favor of that of system-level bureaucrats. She identified several areas in which there could be tension between current Dutch legal practice in the field of automated chain decisions and, especially, legal principles of equality and non-discrimination and the right of defense. One particular problem she identified is that the underlying decision rules of rule-based systems are often not available in a form in which they can be assessed. ${ }^{37}$ Another problem is that it can be difficult for citizens to correct an incorrect registration of their personal details, which may -until corrected- be considered an undeniable 'truth' for other agencies and be used for several automated chain decisions. This sometimes creates Kafkaesque situations, in which citizens can easily get frustrated and feel 'lost in the dataspace'.

As another example of recent research into the field of rule-based systems, Lokin ${ }^{38}$ concluded that the process from legislation to rule-based system is often not fully transparent. Her research focused on the route and different stages, procedures and methods through which administrative legislation ultimately ends up in rule-based systems. On the basis of a study of concrete applications used by the Dutch Tax and Customs Authority and the Immigration and Naturalization Agency, she concluded that the preliminary knowledge models, used to build the rule-based systems that execute the legislation, are often not based on a direct analysis and interpretation of the legislation. Where this is the case, there are no tools for the unambiguous interpretation of the legislation available. ${ }^{39}$ She found that in practice there is relatively little or no direct exchange of knowledge and information between legislative professionals at state departments -"the world of law drafters"- and the professionals that work at executive government agencies and are responsible for the design and programming of the rule-based administrative systems -"the world of system designers"-. ${ }^{40}$ Partly because of these factors, there is no guarantee that in the conversion process from legislation to rule-based system, to put it simply, information is not 'lost'. Consequently, the system may not fully

\footnotetext{
33 Uitvoeringsinstituut Werknemersverzekeringen (UWV), www.uwv.nl

${ }^{34}$ Belastingdienst, www.belastingdienst.nl

${ }^{35}$ Sociale Verzekeringsbank (SVB), www.svb.nl

${ }^{36}$ Marlies van Eck, Geautomatiseerde ketenbesluiten \& rechtsbescherming: Een onderzoek naar de praktijk van geautomatiseerde ketenbesluiten over een financieel belang in relatie tot rechtsbescherming, Tilburg: Tilburg University, 2018, p. 440

37 lbid. p. 446-448

38 Mariette Lokin, Wendbaar wetgeven, De wetgever als systeembeheerder, "NILG serie: Governance \& Recht", Den Haag: Boom Juridisch, 2018

39 Ibid., p. 297

40 Ibid., p. 299
} 
comply with the original objectives or wording of the legislation. Her research suggests several ways in which the legislative process can be improved to facilitate the conversion of legislation to rulebased systems and meet demands of legitimacy and transparency.

Partly based on the research by Lokin and Van Eck, the Dutch Council of State recently issued a report ${ }^{41}$, in which it advised the Dutch central government to take effective measures to counter the negative effects of digitization and automation for citizens. By the same token, the Dutch Ombudsman issued a report, based on complaints and real case-studies, that summarized the negative effects citizens suffer from a digitized and automated government. ${ }^{42}$ The countermeasures against negative effects of digitization and automation that both institutions suggest focus on accessibility, user-centered design, effective support for citizens who experience difficulties using digital systems and efficient, transparent and easily accessible procedures to correct incorrect registrations.

In general, as rule-based systems and automated chain decisions play such an important role in Dutch legal practice, and have done so for decades, there is a remarkable dearth of research on the subject. The issues Lokin and Van Eck raised, combined with the reports of the Council of State and the Ombudsman, are important and justify intensive future research, especially as automated administrative decision-making by government agencies can only be expected to grow in the years to come.

\subsection{Systems for use by government or corporate legal departments ${ }^{43}$}

Legal departments, both within public, corporate and non-profit organizations, can be considered internal legal service providers to their own organizations. A fair amount of the work of many legal departments is of a repetitive nature, and would, in theory, be suitable for support by decision support systems. Our research shows that currently just a small group of front-runners uses DIY software to develop decision support systems, although a broader group of departments is interested and considers experimenting. Respondents indicate, and our own experiences confirm this, that building these systems is not the most time-consuming task. Rather, it is the preliminary research and analysis of the underlying process(es) that are most time-intensive, yet form an indispensable precondition for a decision support system to be successful. As an important reason for the relatively slow adoption of these systems, respondents indicate that very few legal departments reserve or can spare time for true innovation, due to their high work load and relatively small staff. In the Netherlands, being a small jurisdiction, only a few hundred organizations have sizeable legal departments (e.g. >20 staff) and only a few large multinationals and large financial institutions have departments with over 100 legal professionals. Because legal departments are relatively small and are, within organizations, usually viewed as cost-centers, it is not surprising that just a few legal departments have separate budgets for research and development. ${ }^{44}$ As an additional factor that contributes to the slow adoption rate, respondents and our experiences indicate that legal professionals working at legal departments regularly lack basic knowledge and skills in the field of process analysis and implementation of information technology within organizations. To fill this gap in legal practice, some law firms, such as Kennedy van der Laan ${ }^{45}$,

\footnotetext{
${ }^{41}$ Raad van State, 'Ongevraagd advies over de effecten van de digitalisering voor de rechtsstatelijke verhoudingen', 2018. Url: https://www.raadvanstate.nl/adviezen/zoeken-in-adviezen/tekst-advies.html?id=13065

42 Nationale Ombudsman, 'Hoezo MijnOverheid?, Onderzoek naar knelpunten voor burgers bij MijnOverheid / de Berichtenbox', rapportnummer: 2017/098, Den Haag: Nationale Ombudsman 2017. Url: https://www.nationaleombudsman.nl/system/files/onderzoek/DEF\%20Rapport\%2OHoezo\%20MijnOverheid.pdf 43 Parts of paragraph 5.3 and 5.4 are based on Timmer (2019), supra note 8

${ }^{44}$ As one of the respondents phrased it: "I do sometimes feel that our organization is like the cavemen in the cartoon, pushing a cart with square wheels, claiming that they're too busy pushing the cart to switch to round wheels. It's hard to break out of the vicious circle."

45 https://www.synclegal.nl/
} 
expand their service portfolio by developing tailor-made decision support systems for legal departments of their client organizations.

Both in public and private organizations, most notably the latter, drafting and reviewing contracts form an important part of the work of legal departments. Due to their repetitive nature, routine contracts -and similar legal documents, such as proxies- are suitable candidates for (semi)automation ${ }^{46}$. Many (corporate) organizations commonly close thousands of similar types of contracts every year, with just a few variations in the individual contracts. In addition, even contracts with a more bespoke character often have many elements in common with other contracts. Some of the available DIY software on the market is targeted especially towards digitally supporting the drafting of contracts (this type of software is also called: contract automation software). Respondents indicate that contract automation in the Netherlands is still in its infancy, but that the number of organizations using the software is growing. In most of the organizations the software is used to enable non-legal departments (e.g. sales, procurement, research and development) to draft routine, high-volume contracts, such as non-disclosure agreements (NDA's), non-strategic procurement agreements or licensing contracts. These types of contracts often only have a few decision points that are translated into questions in a questionnaire. Based on the answers, the contract is then compiled, combining the user's input and pre-existing text blocks. Examples of questions can, for example, relate to the amount and nature of the goods procured and the characteristics of the counterparty, or to matters such as: Should both parties to the NDA have a non-disclosure obligation, or just one? We encountered relatively few contracts of a more complex nature that were automated, although this could be a logical next step, after organizations have mastered the automation of the simplest contracts.

Respondents indicate that important benefits of using software to automate the drafting process, versus the old situation in which professionals used digital templates, is that the software automatically keeps track of the contracts that are being drafted and that the chance of different templates being used throughout the organization is minimized, because the system acts as a 'single point of truth'. One respondent indicated that automation of their NDA-process saved the legal department approximately five percent of their total budget, while improving quality. Another respondent had designed a system that automated the drafting of procurement contracts. The system also provided a risk assessment of the contracts, determining whether or not the contract should be subjected for review by a specialized legal professional, thus significantly reducing the workload for the legal department. Under the influence of these developments, the role of legal departments will increasingly change from drafting and evaluating individual contracts, to managing contracting processes. ${ }^{47}$ Respondents indicated that user-friendliness and well-planned implementation were key factors to success. Most systems in use were targeted towards non-legal professionals, but some had also experimented with systems for legal professionals. Interestingly, respondents reported that legal professionals were reluctant to use rule-based systems, unless the system would actually save them time. If not, these professionals would often demonstrate a strong tendency to work around the system, undermining its effectiveness. ${ }^{48}$

Another way in which decision support systems are used in the context of legal departments is for the triage of legal questions that other professionals or departments within the organization may have. Especially in large organizations, other departments or professionals often do not know to which professionals at a legal department they can turn with certain questions, partly because they may find it hard to diagnose their own problem in legal terms. Decision support systems can help to

\footnotetext{
${ }^{46}$ For an example from German legal practice, see Stephanie Brtka, Andreas Keller and Dan-Alexander Levien, 'Legal Tech Made to Measure, the Contract Drafting Process with the Audi DocCreator', in Hartung, Bues, Halbleib (2018), supra note 3, p. 150-155

47 See also, Ivar Timmer, 'Changing roles of legal: on the impact of innovations on the role of legal professionals and legal departments in contracting practice'. Journal of Strategic Contracting and Negotiation 2(1-2), 2016:34-47

48 See more extensively, Timmer (2019), paragraph 4.6, supra note 8
} 
do (part of) the triage of legal questions, by helping professionals answer questions such as: what is the core of my problem in legal terms, what is the basic legal framework and to which legal professional at the legal department should I turn for help? It is our experience that for this purpose simple questionnaires are more effective than plain text on an intranet page and could help nonlegal professionals to clarify their question. For example, at the time of completion of this article, one of the authors, together with law students who specialize in the field of decision support systems, was designing two systems for the municipality of Utrecht. The first system assists nonlegal professionals in deciding when, in compliance with Dutch and EU-law, goods or services can either be legitimately subsidized, procured without a formal procedure, or would have to be subjected to a public tender procedure. The other helps professionals determine which professionals in the organization, and under which specific conditions, have the authority to perform legal acts. These topics were selected because the legal department receives several hundreds of questions yearly on these matters, many of which are relatively straightforward and can be answered by asking just a few specific questions.

The experiences of respondents demonstrate clearly that user-friendless and a thorough design process involving all relevant stakeholders and ideally comprising several test rounds with real users, is essential to the successful implementation of these types of systems. Many respondents provided examples in which attempts to implement decision support systems had failed, because the system was not user-friendly enough and/or stakeholders were not involved. Others reported that some legal professionals may feel that decision support systems undermine their professional autonomy. The causes of these failures resemble some of the causes mentioned in the discussion of the history of rule-based systems in paragraph 4, underlining the importance of awareness, knowledge and skills in the field of design and implementation of technology.

From the perspective of legal principles and protection of rights, there are few objections to organizations using software to digitize and automate their internal legal processes. This may be different where decision support systems are used to deliver legal services to citizens, see also the previous subparagraph. In the next subparagraph we will explore some possible implications if rulebased decision support systems are offered as self-help tools to consumers.

\subsection{Systems for legal advice and legal aid to private individuals}

Contracts not only play a part in the realm of legal departments and large organizations, but are also important for consumers and small and medium-sized enterprises (SME's). In recent years, several alternative legal service providers have entered the Dutch consumer market to provide online selfhelp tools for contracts and other legal documents for consumers and small businesses. They often combine this with functioning as an online market place for law firms, notaries or other legal service providers that serve customers who need more advice. Examples are Overeenkomsten.nl, Omnius ${ }^{49}$ and JuriDox.nl. In 2013, large Dutch retailer HEMA entered into a partnership with some notary firms and launched an online notary service for several standard documents (e.g. a basic last will). ${ }^{50}$ This sparked an intensive debate among notaries about whether (partly) digitizing this process was in line with their professional code. In 2015, after an investigation and a complaint by the Royal Dutch Association of Civil-Law Notaries, the highest disciplinary judge ruled that the collaboration between the notaries and HEMA was allowed, because the notaries involved had sufficient control and supervision over the provision of services and, for example, always performed a final check. ${ }^{51}$

The use of decision support systems as 'pure' self-help tools to draft contracts for private use is different, as there is no control or supervision by legal professionals. Until now, we know of no legal

\footnotetext{
${ }^{49}$ https://www.omnius.nl/doe-het-zelf/

50 https://notarisservice.hema.nl/

${ }^{51}$ See https://uitspraken.rechtspraak.nl/inziendocument?id=ECLI:NL:GHAMS:2015:2270
} 
proceedings by consumers or SME's that have ran into problems because they had used a contract offered by one of the self-help tools. In the US, which has far stricter rules on the unauthorized practice of law, Legal Zoom, an online provider of self-help tools for contracts and legal documents, faced litigation in several states, but is now considered not to offer legal advice. ${ }^{52}$ Pragmatically, one could argue that consumers and SME's might be better off using a professional self-help tool for a small fee, than trying to construct a legal document themselves by using templates they find on the internet. However, quality standards should be raised once the tool aims to (partly) replace legal aid professionals and/or provide specific legal advice for people who face more complex legal problems. Examples in the Netherlands include Appjection ${ }^{53}$, developed by law students from Leiden University to fight traffic tickets. What started as a chatbot service, is now slowly turning into an expert system that not only generates legal documents to fight the actual fine, but can also provide the chances of success without the interference of human legal experts. Based on the same principle there is Flightclaim ${ }^{54}$, which helps people to obtain refunds after delayed flights. There are also systems being developed in the field of consumer law. ${ }^{55}$

Two of the most complex systems in the Netherlands, which most will agree qualify as 'true' expert systems, are UitElkaar ${ }^{56}$, an application for divorce law, and MagOntslag ${ }^{57}$ for labor law. With UitElkaar, married couples facing divorce, can go to the website and answer questions individually. The application was developed with a great deal of attention for the 'soft side' of a divorce, as it is one of the most emotionally charged legal procedures. For a fixed fee and upon mutual agreement of both parties, all necessary documents are created and, if necessary, a mediator can be consulted. The fixed fee includes court fees. With the MagOntslag application, employees or employers facing the question if dismissal is allowed, answer questions on the website. An interactive questionnaire navigates the user through the website. The system contains over 2000 questions, but since the answers given determine the questions posed, users will never have to answer all of them. The outcome is an evaluation of the user's legal position. If that position is worth litigating or, preferably, negotiating, the system produces customized legal documents to use in negotiations with the other party or, if necessary, the court. The system is calibrated and validated on a daily basis. MagOntslag is in essence an enormous, interactive decision tree, that uses 'if... then...-formulas', as well as more complex algorithms that weigh answers or combinations of answers. Especially this last aspect distinguishes sophisticated expert systems from less complex ones.

Although unavoidable, this complexity makes developing and maintaining rule-based systems that provide legal aid to individuals extremely resource-intensive. For example, MagOntslag was created and developed by a team of scholars, specialized in labor law and skilled in the technology behind rule-based systems. The system also aims at anticipating situations that have not yet been presented to court (at least not according to published rulings) and thus requires researchers to be able to fill in these gaps by interpreting legislation and case law. At the same time, standards of user-friendliness require that the system uses understandable language, implying that legal terminology has to be translated into 'normal language', or at least explained, without altering the legal meaning. The system has to be tested on a regular basis to keep it up-to-date. Considering these requirements, it is

\footnotetext{
52 See more extensively

http://www.abajournal.com/magazine/article/latest_legal_victory_has_legalzoom_poised_for_growth

53 https://www.appjection.nl.

${ }^{54} \mathrm{https}$ ///flightclaim.com.

${ }^{55}$ At the time of writing, the team of MagOntslag in combination with other parties was working on a system for noncompliance and one of the legal insurances in the Netherlands, ARAG, is ready to present a service for delayed parcel delivery, which is related to Appjection and Flightclaim .

${ }^{56}$ https://www.uitelkaar.nl. The initiative came from HiiL and the Raad voor Rechtsbijstand', the Dutch Legal Aid Board.

57 https://www.magontslag.nl, developed by a private company that is part of the University of Amsterdam.
} 
understandable that creating an economically sustainable model is challenging, especially because an important goal of the project is to offer the service to users at an affordable rate.

For the avoidance of doubt, the objective of MagOntslag is not to replace lawyers and judges. To discuss at length why this is not a good idea falls beyond the scope of this article, but arguments include the right to a fair trial, the right to be heard and GDPR-related ${ }^{58}$ restrictions. Even if some of these problems would be solved, there are various other legal and ethical aspects. One of the most important ones is that systems cannot fully understand a human being's emotions and interests, and therefore cannot meet the requirements of high-quality legal aid. Therefore, in our opinion, rulebased systems in the context of legal aid and advice should be used as support and aid to individuals seeking justice and as guidance for legal experts, who should ultimately make their own normative decisions.

From the perspective of the use of these types of systems, there are also several possible pitfalls. First, the more algorithms are used and the more detailed questions users have to answer to obtain actions, the less transparent it becomes how predictions are produced, see also paragraph 4 on the "black box" problem. Although, unlike a data-centric system, a rule-based system is essentially transparent, in practice it can be difficult to demonstrate how the prediction is produced. With MagOntslag one of the solutions is to draw "weighing schedules"', which give the developer, as well as any other viewer, a clear insight into what combinations of answers lead to certain outcomes. Formatted as a table, every possible route to distinct outcomes. Also, as mentioned in paragraph 4, programmers and developers are not infallible and both technical and legal flaws may enter the system. Testing and falsifying the systems with numerous -real or fictitious- cases is a time-consuming, but indispensable measure to prevent errors.

Another widely discussed possible downside of the use of expert systems is the risk of biases being programmed into the systems. Specific biases of an individual judge will normally be ruled out by the fact that the system is based on the rulings of a large number of judges, but a rule-based system could reinforce systemic biases. Users of a rule-based system could suffer from the so-called automation bias, which could also be referred to as the "computer says no" syndrome. This could be described as a strong tendency to adhere to a suggested outcome of the system, even in the presence of good arguments to deviate from this suggested outcome. It is especially essential for professional users to realize that systems are fallible and that the nature of a rule-based system is static, while reality and the law are dynamic. Legal experts should not be afraid to challenge the system and use their discretionary authority. In theory, an expert system could become dominant by favoring specific outcomes. We believe that this risk is especially real in the governmental systems for mass administrative decision-making, see also Van Eck. ${ }^{59}$ Nevertheless, it is important to be aware that other rule-based systems could also become dominant and prevent the necessary legal innovation. ${ }^{60}$ However, our experiences with MagOntslag show that the extensive research that is necessary to develop and maintain a rule-based system will also discern unjustified discrepancies between rulings and judges. In this manner, the development of rule-based systems may also have a desirable harmonizing effect.

Notwithstanding the risks and pitfalls discussed above, we believe that in our digital age well-designed and maintained expert systems can play an important factor in supporting the provision of legal aid and advice, improving access to justice, as well as the user-friendliness of legal services and legal

\footnotetext{
58 Under GDPR, art 22(1) there is the right not to be subject to a solely automated decision with legal effect. See for more Guido Noto La Diega, 'Against the Dehumanisation of Decision-Making, 9 (2018) JIPITEC 3 para 1.

59 Van Eck, supra note 47 , p. 446-448

60 Ira L. Dove, 'Legal expert systems: the end of jurisprudence', The Journal of Legal Studies in Business, 1996, Vol. 5.
} 
security, equality and certainty. Lessons from the past teach us that user-centered design is a key factor to take into account. To quote Greenleaf, from his 1989 article $^{61}$ :

"We have seen that the idea of 'the computer as a robot lawyer' is a misconception of the aims of legal expert system research. The only feasible model is one based on the continuing interaction between an expert user-interpreter (a lawyer) and a semi-expert program, with control of the reasoning process alternating between the two partners to the interaction.

Seen from this perspective, the task of developing legal expert systems is feasible, useful and still just as challenging."

\section{Conclusion}

In this article we have painted, in broad strokes, an image of the use of rule-based systems in different areas of Dutch legal practice. It is clear that these systems play an important role in current legal practice. Their use can only be expected to increase, both in the field of mass administrative decisionmaking and in smaller scale contexts, such as in the provision of legal advice and legal aid to private individuals or the use by law firms, other legal service providers and in-house legal departments in the delivery of (in-house) legal services to clients. As mentioned in the introduction, considering the impact of these systems on legal practice, there is a dearth of research on the subject. Because the underlying technology is relatively straightforward, it is understandable that the academic attention of legal informatics has shifted towards more advanced technologies. However, other areas of legal science should be interested in the real-life effects that these systems have. The research by Van Eck and Lokin and the reports by the Dutch Ombudsman and Council of State justify more scientific research into the detrimental effects of digitization and automation of governmental legal decisions and services, as well as research into the effectiveness of possible countermeasures. The increased use of self-help tools and rule-based decision support systems that provide legal aid and advice to private individuals and SME's also raises important questions. Rule-based systems may be part of the solution to keep legal aid and advice in the Netherlands affordable and thus help sustain a high level of access to justice. However, these systems may have negative side-effects. Both the possible positive and negative impact justify further research. In general, the factors that could contribute to effective user-centered design and implementation of rule-based systems -or technology in general-, including possible pitfalls such as resistance by professionals or users, are valuable research subjects for the emerging fields of legal management and legal service design. The many legal tech labs emerging around the globe could perform a useful role here.

Although the technology behind rule-based systems may be relatively simple and has been around for decades, this does not mean that there will be no innovation in this area of legal tech. Although our focus has not been on this aspect, the near future will see interesting combinations of rule-based systems with data-centric approaches. For example, this could mean that a legal professional uses a rule-based system to construct the basis of legal documents, while a data-centric system automatically suggests prior related cases -on the basis of characteristics of the case- that could be used to construct effective arguments. Dutch legal publishers already plan releases of software that combine the two approaches.

Our focus has not been either on the impact of technology on the labor market for legal professionals. Despite what stories in mass media and other research may indicate, our research does not lead us to expect technology to soon replace large parts of the work of legal professionals. ${ }^{62}$ In discussions on

\footnotetext{
${ }^{61}$ Graham Greenleaf, 'Legal expert systems - robot lawyers?', presented at the Australian Legal Convention, Sydney, August 1989.

62 For a more realistic approach, see Remus and Levy, supra note 18
} 
the impact of technology on the legal labor market, few appear to realize that over the past decades (search) technology has greatly improved the efficiency of legal professionals, while the overall number of professionals working in legal practice has only increased. At least for now, it appears that the juridification of society has outrun technology's ability to increase the efficiency of legal professionals. We see no evidence that this trend is about to change. That having said, technology will certainly change the legal profession. ${ }^{63}$ We believe that legal professionals and legal scholars should urgently increase their knowledge and skills in the area of (implementation of) technology to adequately respond to the challenges that our digital society poses.

\footnotetext{
${ }^{63}$ See also, Micha-Manuel Bues and Emilio Matthaei, LegalTech on the Rise: Technology Changes Legal Work Behaviours, But Does Not Replace Its Profession, in Kai Jacob, Dierk Schindler and Roger Strathausen, Liquid Legal, Transforming Legal into a Business Savvy, Information Enabled and Performance Driven Industry, Heidelberg: Springer, 2017
} 